\begin{tabular}{|l|l|}
\hline & \\
&
\end{tabular}

SEÇÃO: ARTIGOS E ENSAIOS

\title{
Assistência social e as comunidades quilombolas do Brasil ${ }^{1}$
}

Social assistance and quilombolas communities in Brazil

\section{Sidimara Cristina \\ Souza ${ }^{2}$}

orcid.org/0000-0002-8704-7340

sidi.mara@hotmail.com

\section{André Augusto Pereira \\ Brandão ${ }^{2}$}

orcid.org/0000-0002-9245-0273

andre_brandao@id.uff.br

Recebido em: 2 jun. 2020.

Aprovado em: 16 nov. 2021.

Publicado em: 29 dez. 2021.
Resumo: Este artigo analisa o processo de operacionalização da Política de Assistência Social a partir da perspectiva do Sistema Único de Assistência Social (SUAS). A pesquisa que originou estas reflexões utilizou como procedimento metodológico a entrevista semiestruturada, aplicada junto aos implementadores e gestores da politica de assistência social. A amostragem foi restrita a municipios onde se localizam comunidades quilombolas certificados pela Fundação Cultural Palmares, no território do Vale do Mucuri, Minas Gerais, Brasil. Dessa forma, nossa investigação deteve-se nos municipios de: Carlos Chagas, Ouro Verde de Minas, Pescador, Teófilo Otoni e Ataléia. Com a sistematização dos dados, concluímos que o acesso à política de assistência social é mínimo e desconsidera a identidade coletiva desta população tradicional. Mesmo sendo a política de assistência social reconhecida como direito, ainda é ofertada apenas para aqueles que são atestados como extremamente miseráveis e não para os que dela necessitam, reproduzindo o estigma de "politica de pobre para pobre".

Palavras-chave: Assistência Social. Remanescente de quilombo. Política Social.

Abstract: This article analyzes the operationalization process of the Social Assistance Policy from the perspective of SUAS. The research that gave rise to these reflections used the semi-structured interview as a methodological procedure, applied to the implementers and managers of the social assistance policy. The sampling was restricted to municipalities where quilombola communities certified by Fundação Cultural Palmares are located, in the territory of Vale do Mucuri, Minas Gerais, Brazil. Thus, our investigation was conducted in the municipalities of: Carlos Chagas, Ouro Verde de Minas, Pescador, Teófilo Otoni and Ataléia. With the systematization of the data, we conclude that access to the social assistance policy is minimal and disregards the collective identity of this traditional population. Even though the social assistance policy is recognized as a right, it is still offered only to those who are considered extremely miserable and not to those who need it, reproducing the stigma of "poor to poor policy".

Keywords: Social Assistance; quilombo remnant; social policy.

\section{Introdução}

A Constituição Federal brasileira significou um marco no que tange ao sistema de proteção social, responsabilizando o Estado pela garantia de direitos humanos e sociais aos individuos. Contudo, ainda estamos em estágio incipiente, no que diz respeito à cobertura de todos que necessitam da proteção social estatal. Mesmo após 31 anos da finalização da Constituição Federal de 1988, não estamos preparados para resguardar os direitos dos diversos usuários que não se enquadram

\footnotetext{
1 O presente trabalho foi realizado com apoio da Coordenação de Aperfeiçoamento de Pessoal de Nivel Superior - Brasil (CAPES) - Código de Financiamento 001.

1 Universidade Federal Fluminense (UFF), Niterói, RJ, Brasil.
} 
dentro da perspectiva da totalidade, indo além das variáveis gênero, geração e pobreza, além de estarem na esfera da "vulnerabilidade ou risco social". Negamos a individualidade, a identidade dos sujeitos da politica social e atribuímos uma única: de um homem ou mulher, criança ou adolescente, jovem ou idoso que necessita de atendimento, sem levar em consideração os significados existentes na construção de cada ser. De fato, o que vemos é uma "espécie de 'cultura política' que nega a identidade social dos subalternos e seu pertencimento a uma classe; tratamos de uma forma de ocultar o conflito e a resistência e de legitimar a dominação" (YAZBEK, 1993, p. 41).

Por isso, consideramos que é necessário apreciar os eixos estruturantes e interseccionais dessa sociabilidade capitalista como: raça, gênero e classe e de demarcadores da diferença como: geração, sexualidade, religião e outros. Tal "esquecimento" faz com que o processo de operacionalização da política de assistência social seja realizado sem garantir a equidade e a tão falada universalidade. Pois, muitos usuários deixam de acessar a rede de proteção social por não se sentirem contemplados. A ocorrência dessa situação cria uma distinção entre os próprios assistidos.

No intuito de refletirmos criticamente sobre a política de assistência social e os usuários remanescentes de quilombos é que estruturamos este artigo. Para isso, buscamos analisar as comunidades quilombolas como um grupo com identidade estigmatizada e usuários em potencial da assistência social. A escolha do grupo se deve ao fato de conterem núcleos familiares discriminados historicamente e que sofrem de forma significativa os reflexos da questão social. Fatores que os colocam enquanto possiveis usuários da assistência social, embora também demandem ter suas identidades resguardadas e valorizadas. A pesquisa realizada foi de matriz qualitativa, junto a implementadores e gestores, utilizando como procedimento metodológico entrevistas semiestruturadas em cinco municipios do Estado de Minas Gerais que têm comunidades quilombolas certificadas em seus territórios, sendo eles: Teófilo Otoni, Carlos Chagas, Pescador, Ataléia e Ouro Verde de Minas que tinham em seus territórios comunidades quilombolas certificadas pela Fundação Cultural Palmares.

Para a realização deste estudo, entrevistamos 22 profissionais, sendo seis gestores (individuos vinculados à liderança da Secretaria de Assistência Social de cada município estudado) e 16 implementadores. Em Ouro Verde de Minas, foram entrevistados dois gestores, pois a cidade apresenta duas pessoas na linha de frente da Secretaria de Assistência Social. Teófilo Otoni foi o único municipio em que realizamos seis entrevistas. Isso ocorreu, porque somente lá encontramos um CREAS e um CRAS Rural.

Partimos do pressuposto que mesmo na contemporaneidade, os usuários da política social brasileira, em especial da assistência social, são vistos como beneficiados e não como cidadãos de direitos. Acreditamos que grande parte dos grupos minoritários: população negra, povos e comunidades tradicionais (PCTs), população LGBTSX, e outros, ainda se enquadram nessa situação. Uma vez que a assistência social para muitos só se efetiva por meio dos benefícios eventuais, destinados para situações emergenciais extremas.

\section{Quilombolas: usuários em potenciais?}

De acordo com a Fundação Cultural Palmares (2019), hoje o universo de grupos étnicos reconhecidos como remanescentes de quilombos chega a compor um quadro de 3.018 comunidades. Desse montante, 2.744 são reconhecidos oficialmente pelo Estado brasileiro e possuem a certificação emitida pela Fundação. Nesse universo, apenas 220 títulos de posse definitiva das terras foram emitidos, beneficiando 294 comunidades e 15.910 familias quilombolas.

Segundo dados do painel de monitoramento da SEPPIR 3 atualizado até maio de 2017, pouco mais de $50 \%$ das casas quilombolas utilizam a

3 Extintos do sistema online desde a extinção da SEPPIR. 
fossa rudimentar para escoamento sanitário. 0 mais agravante é que quase $10 \%$ têm seus dejetos despejados em valas a céu aberto. Em relação às fontes de abastecimento de água, quase 50\% das familias quilombolas só têm acesso à água por meio de poços ou nascentes.

De acordo com Brandão et al. (2010), as principais fontes de abastecimento de água das quase 200 comunidades quilombolas pesquisadas por eles em 2006 e 2008, eram os rios, córregos e riachos, atingindo 31\% do universo total. Apenas 29\% dispunham de água ofertada por via de rede pública. Se o acesso à água tratada já é restrito, o acesso à coleta de lixo é ainda mais deficiente. Segundo a SEPPIR (2017), apenas 26,9\% dos domicilios quilombolas são atendidos pelo serviço.

No que diz respeito às condições econômicas das comunidades quilombolas, podemos afirmar que estão inseridas em uma situação de extrema pobreza. Em mais de 70\% das familias remanescentes de quilombo a renda familiar não ultrapassa $R$ \$ 77 reais. A SEPPIR (2017) alega que a renda média per capita das famílias quilombolas varia de $\mathrm{R} \$ 483$ a $\mathrm{R} \$ 16$. O que faz com que $80 \%$ das familias quilombolas inscritas no Cadastro Único (CadÚnico) sejam beneficiadas com o Programa Bolsa Familia.

De acordo com a SEPPIR (2017), 94.531 quilombolas com idade igual ou superior a 15 anos possuem no máximo o ensino fundamental completo. Em 2013, a SEPPIR diagnosticou, por intermédio do Cadúnico, que 24,81\% dos remanescentes de quilombos não sabiam ler; $82,2 \%$ desenvolviam atividades agricolas, extrativistas ou pesca artesanal. O universo pesquisado foi de 2.197 comunidades (sendo 2.040 certificadas e 157 tituladas).

Os dados apresentados são uma amostra da situação em que se encontram as comunidades remanescentes de quilombo do Brasil. Contudo, ainda precisamos elencar um dado primordial que atinge boa parte das familias quilombolas: o racismo. Ao se reconhecerem formalmente como quilombolas, o grupo se assume diante da sociedade como uma comunidade negra e, consequentemente, os membros das comunida- des são expostos a diversas situações discriminatórias. Conforme nos descreve Almeida (2016), as familias negras são invisibilizadas diante da estrutura de dominação da supremacia branca. As famílias extensas formadas pelos negros, como as comunidades remanescentes de quilombos, articuladas como mecanismo de resistência e luta, em grande parte foram criminalizadas pelo Estado e ainda são recriminadas pelo ódio dos que se identificam como superiores.

A situação de vulnerabilidade social em que se encontram as comunidades quilombolas gera impactos significativos sobre suas familias, e exige do Estado medidas que busquem reverter o quadro da extrema pobreza. As mazelas advindas tanto de questões culturais, acirradas por uma desigualdade de classe, são elementos que impulsionam a luta pelo reconhecimento dos sujeitos de direitos e, com isso, a entrada da discussão do assunto nas agendas políticas e a implementação de ações contextualizadas e efetivas.

\section{O processo de implementação da política de assistência social nas comunidades quilombolas}

Desde o reconhecimento da assistência social como direito, muitos avanços foram obtidos, assim como sobrevieram grandes desafios para efetivar as conquistas obtidas. De acordo com a análise situacional que sustenta o desenho da PNAS, a política tem o objetivo de dar visibilidade para aqueles que foram invisibilizados na sociedade brasileira, como é o caso de quilombolas, indigenas, deficientes, entre outros. A PNAS prevê a garantia de equidade para os segmentos que estão expostos a maior risco social. Nessa perspectiva, a NOB/SUAS de 2005 orienta que a presença de comunidades quilombolas nos territórios seja considerada como indicador complementar para realização da análise socioterritorial dos municipios dentro da variável de especificidade regional. Esse dado se junta a outros como: taxa de urbanização, taxa de intensidade da pobreza, taxa de crescimento da população residente e taxa de evasão escolar. 
De acordo com a NOB/SUAS (2005):

O estabelecido em relação às características dos municípios de acordo com seu porte é regra geral a ser seguida no processo de cofinanciamento da política de Assistência Social. Há, no entanto, grande possibilidade de ocorrerem situações especificas, não passiveis de tratamento generalizado. Tais situações deverão ser consideradas como tal, levando ao desenvolvimento de ações voltadas ao seu atendimento também de maneira específica, inclusive na diferenciação de trato quando da definição dos critérios de partilha e de transferência de recursos federais e estaduais. É o caso, por exemplo, das realidades de seca, fronteira, ribeirinha, portuária, quilombola, indigena, de floresta, bem como das realidades em que são altos os índices de mortalidade juvenil, entre outras, em que o custo dos serviços será calculado a partir da complexidade da situação e das demandas especificas que apresentam, objetivando chegar à pisos variáveis mais especificos dentro de cada nivel de proteção (NOB/SUAS, 2005, p. 152).

A partir das orientações e das ponderações dos marcos normativos e legais da política de assistência social brasileira, podemos afirmar que há previsão de assistência social às comunidades quilombolas. Contudo, quando questionamos os implementadores e os gestores sobre essa previsão, muitos a desconhecem. Os relatos são de que a política precisa ser executada da mesma forma para todos, independentemente da condição de quilombolas ou não.

Segundo a representante do CRAS de Teófilo Otoni, a política de assistência social local não prevê assistência aos quilombolas:

[...] não é discutido a menos que surja um caso específico. A Politica de Assistência Social, hoje, assumiu um volume de interface de articulação, de atuação tão grande que infelizmente não sobra esse espaço para planejamento e para pesquisa de questões que não fazem parte dessa demanda que chega ao CRAS (Representante do CRAS de Teófilo Otoni, informação verbal). ${ }^{4}$

De acordo com a equipe de Pescador, a política prevê assistência às comunidades quilombolas, mas: "[...] só tenta mesmo fazer aquilo que é, assim, o mínimo, que é estar dando essa assistência lá... com o serviço de convivência, com o Programas Bolsa Família que já existe..." (Entrevistado de Pescador, informação verbal). ${ }^{5}$

A representante da gestão de Ouro Verde, afirma que a política em questão prevê assistência às comunidades quilombolas, mas, na realidade deles, isso não é levado em questão. De acordo com este, "tem (a politica), mas no nosso caso aqui, é, não tem, nós não atendemos assim especíico para aquela comunidade não. Até pelo fato de sermos poucos, pouca equipe, então a gente não faz um trabalho específico lá não, mas tem sim" (Representante da gestão de Ouro Verde, informação verbal). ${ }^{6}$

Percebe-se, no processo de execução da política de assistência social, um distanciamento do que está previsto em âmbito nacional e o que os municípios de fato interpretam como sendo a política. O desconhecimento do desenho político proposto faz com que parte do que se busca efetivar fique apenas no papel, pois a falta de conhecimento, tanto da política como da própria especificidade regional, conduz à inoperância do sistema como um todo. Tanto os gestores como os implementadores acreditam que prever assistência às comunidades quilombolas equivale a criar serviços que contemplem um grupo em especial. Eles desconsideram a possibilidade de priorizar o atendimento, sem excluir. É importante ressaltar que priorizar não significa excluir os demais sujeitos, mas sim distinguir, considerar que existe no território uma desigualdade que precisa ser superada. Para isso, é preciso atuar de modo a garantir que todos tenham as mesmas oportunidades, mas com atendimento diferenciado.

Para os entrevistados, a implementação dos serviços e programas sociais nas comunidades quilombolas deve ser igual a de todos, pois a prioridade pode se tornar uma injustiça com os

\footnotetext{
4 Depoimento do(a) implementador(a) da política de assistência social do município de Teófilo Otoni-MG à pesquisadora Sidimara Cristina de Souza, em entrevista realizada em 2020.

5 Depoimento do(a) implementador(a) da política de assistência social do município de Pescador-MG à pesquisadora Sidimara Cristina de Souza, em entrevista realizada em 2020.

6 Depoimento da representante da gestão da Política de Assistência Social do municipio de Ouro Verde de Minas-MG à pesquisadora Sidimara Cristina de Souza, em entrevista realizada em 2020.
} 
demais. Segundo eles, trata-se de uma questão de igualdade tratar todos da mesma maneira, sem discriminar nem favorecer um em prol do outro. Contudo, devemos questionar: como garantir o direito dos quilombolas sem atender suas especificidades? Como assegurar os direitos de uma familia homoafetiva sem caracterizar suas especificidades?

Para garantir a igualdade em um país tão preconceituoso e desigual, é necessário agir em prol da equidade dentro de uma estrutura poliárquica, similar à defendida por Robert Dahl (1997). Talvez seja necessário instituir no processo de implementação das políticas sociais o estabelecimento de uma "democrequidade", ou seja, um sistema democrático de direitos que atenda os sujeitos dentro das suas necessidades e condições identitárias e de vida. Uma junção de equidade e democracia no intuito de instituir um sistema de justiça social para todos.

Ao perguntamos para os gestores e implementadores se os programas e serviços de assistência social chegavam às comunidades quilombolas, a maioria dos entrevistados afirmou que sim. De acordo com representantes de Carlos Chagas, eles "chegam e muito bem chegados! Nunca foi negado, principalmente se estiverem dentro dos critérios determinados por cada programa ou serviço" (Representante de Carlos Chagas, informação verbal).7 A gestora de Pescador complementa: "chega, com certeza. Lá é como se fosse, outro bairro aqui. Aqui serve lanche, lá serve lanche, tudo, tudo o que tem aqui. Até o tema que vai ser trabalhado com as crianças aqui, é o que vai ser aproveitado para trabalhar lá". Ela destaca que até as atividades de grupo já chegaram até às comunidades quilombolas, como

o artesanato, que foi desenvolvido já tem muito tempo, agora está retornando aí de novo, as oficinas. Tem a capoeira que é desenvolvida lá também né. E o periodo que eu estava trabalhando, a gente desenvolveu alguns temas, discriminação racial (Gestora de Pescador. informação verbal). ${ }^{8}$
Precisamos refletir se estamos apenas cumprindo metas ou fazendo valer os direitos dos usuários. Não basta apenas implementar da mesma forma em todos os lugares para todos os usuários. Não é uma questão de padronização. É uma questão de garantir acesso, respeitando as diversidades. É garantir equidade e não só igualdade, pois os contextos históricos dos grupos são constituídos por particularidades que precisam ser consideradas. Como garantir empoderamento se desconhecemos a historicidade dos nossos usuários?

Será que podemos afirmar que as comunidades quilombolas são assistidas pela assistência social? A política é composta apenas pelos programas de transferência de renda? Qual a porcentagens de jovens que acessam o ld Jovem? São perguntas que precisamos fazer no cotidiano das nossas práticas profissionais. Acreditamos que a precarização dos serviços e dos programas faz com que estes sejam ineficientes. A ampla divulgação do Bolsa Família, principalmente em periodo eleitoral, faz com que este seja mais conhecido entre os usuários e, consequentemente, mais demandado. Todavia, só o programa bolsa familia é suficiente para caracterizar que a população tem acesso à assistência social? Não estamos reproduzindo uma política minimalista de pobre para pobres? É fato que os benefícios são, para muitas familias, a única fonte de renda disponivel para a sobrevivência. Isso fica claro nos relatórios governamentais e nos estudos acadêmicos existentes. Entretanto, também reconhecemos as fragilidades das propostas, principalmente no que diz respeito às condicionalidades exigidas pelo programa Bolsa Família e ao limite de idade apresentado pelo BPC.

No que tange à implantação de CRAS Quilombolas, constatamos que, em nenhuma das comunidades estudadas, existe uma base de proteção social básica. Entre os cinco municipios pesquisados, em apenas um o gestor já tinha ouvido falar dessa especificidade. A assistente

\footnotetext{
Depoimento do(a) gestor(a) da Política de Assistência Social do município de Carlos Chagas-MG à pesquisadora Sidimara Cristina de Souza, em entrevista realizada em 2020

8 Depoimento da gestora da Política de Assistência Social do município de Pescador-MG à pesquisadora Sidimara Cristina de Souza, em entrevista realizada em 2020
} 
social do CRAS de Pescador "nem tinha conhecimento desse CRAS Quilombola, desse tipo. Eu já participei de 4 capacitações, e nunca ouvi falar do CRAS Quilombola. Não sabia da existência de um CRAS Quilombola" (Assistente Social de Pescador, informação verbal). ${ }^{9}$

Diante dos dados, podemos apontar o desconhecimento da Portaria n 137 de 2006 que, ao considerar as diretrizes da PNAS/2004, determina que as ações devem: "contemplar as minorias étnicas, em situação de vulnerabilidade social, para a implantação e implementação de ações adequadas, com eficácia e efetividade às suas demandas".

A legislação institui as normas de cooperação e financiamento para o processo de implementação de Projeto para a Efetivação da Estrutura da Rede de Proteção Social Básica, que também pode ser chamada de CRAS Quilombolas, CRAS Indígena - e assim sucessivamente - de acordo com a especificidade do público-alvo. Todavia, essa especificidade que compõe o CRAS Itinerante não é conhecida pelos gestores e implementadores da política de assistência social da região de Ouro Verde de Minas, Carlos Chagas, Teófilo Otoni, Pescador e Ataléia - mesmo todos apontando a necessidade de tais equipamentos públicos.

Tanto os gestores como os implementadores relatam a importância do CRAS Itinerante/ Volante. Eles sabem que o objetivo de tal estrutura móvel é atender as familias localizadas em territórios considerados de baixa densidade demográfica ou com população dispersa. Os gestores, porém, não têm consciência de quem são os usuários que se enquadram nessas características, como é o caso de moradores da área rural, quilombolas, indigenas, assentados, entre outros, conforme determina a Tipificação Nacional de Serviços Socioassistenciais (2009). Os entrevistados citam a possibilidade de atendimento das familias quilombolas, mas focam apenas em desafogar o sistema ao poder atender a zona rural como um todo, sendo esse foco apenas um dos objetivos da proposta.

A gestora de Ataléia destaca que a criação do CRAS Quilombola restringiria o atendimento apenas às comunidades. Por isso, o CRAS Volante/Itinerante seria a melhor opção. "[...] porque se eu criar um CRAS Quilombola, aí eu vou cair naquela situação de problema, né, que vai falar assim: eu só vou atender aquela comunidade e aí eu continuo com o problema da zona rural extensa e que não é atendida". (Gestora de Ataléia, informação verbal). ${ }^{10}$

A representante do Bolsa Família do município reforça:

[...] de alguma maneira, o CRAS deveria ser uma
ferramenta de aproximação l...]por causa, por
causa da extensão da comunidade quilombola
em Ataléia, eu acho que não haveria neces-
sidade, que aí poderiamos integrá-los, fazer
um trabalho de união entre esses setores da
sociedade em um único espaço, e eu penso
pelo menos, em nosso contexto aqui, ter um
CRAS quilombola, talvez seria separar, esses
grupos em espaços diferentes, e acho que essa
não deve ser a intenção. (Representante do
Bolsa Familia de Ataléia, informação verbal). ${ }^{11}$

Porém, a Portaria $n^{\circ}$ 136/2006 prevê tais situações e define que caso o CRAS consiga garantir $\mathrm{o}$ atendimento a todas as comunidades quilombolas que estão em situação de vulnerabilidade social e ainda não atingiu o número máximo de atendimentos permitido, o centro poderá fazê-lo até completar o número limite da sua capacidade e, assim, fornecer atendimento aos núcleos familiares que não são quilombolas.

As entrevistadas da Secretaria de Assistência Social de Ouro Verde de Minas e de Pescador relatam que seria importante ter um CRAS Quilombola para atender especificamente às comunidades, uma vez que o número desta vem sendo ampliado: "tinha uma comunidade quilombola só, que é a de Santa Cruz, hoje têm várias comunidades aqui. Então aqui está crescente essa demanda, esses grupos, e aí, para

\footnotetext{
9 Depoimento do(a) implementador(a) da Política de Assistência Social do municipio de Pescador-MG à pesquisadora Sidimara Cristina de Souza, em entrevista realizada em 2020.

10 Depoimento da gestora da política de assistência social do municipio de Ataléia-MG à pesquisadora Sidimara Cristina de Souza, em entrevista realizada em 2020.

11 Depoimento do(a) implementador(a) da política de assistência social do municipio de Ataléia-MG à pesquisadora Sidimara Cristina de Souza, em entrevista realizada em 2020
} 
fazer um atendimento especializado com eles" (Representante da gestão de Ouro Verde de Minas, informação verbal). ${ }^{12}$ Porém, seu colega de trabalho discorda e enfatiza que não há necessidade desse tipo de atendimento. Para ele, o foco deveria ser a melhoria da rede existente.

A carência da estrutura de CRAS Quilombolas é uma realidade em mais de $60 \%$ dos territórios quilombolas certificados no Brasil, de acordo com o Censo SUAS (2017). Podemos justificar a falta desses centros regionais com o próprio desconhecimento por parte da sociedade em geral do status de sujeito de direitos que é devido aos quilombolas. Podemos conferir tal afirmativa a partir das análises realizadas nas entrevistas com os gestores e os implementadores da política de assistência nos municípios estudados.

A viseira intelectual dos gestores e também dos implementadores, sejam psicólogos sejam assistentes sociais, reforça a invisibilidade das comunidades quilombolas. Sabe-se de sua existência, mas não são consideradas de acordo com suas especificidades. Ao contrário, elas são minimizadas e, muitas vezes, excluidas. Esse gargalo faz com que a Politica de Assistência Social seja operacionalizada sem prever atendimento diferenciado para os múltiplos seguimentos da população, apesar de o texto da PNAS ter regulado que

[...] essa política inaugura uma outra perspectiva de análise ao tornar visiveis aqueles setores da sociedade brasileira tradicionalmente tidos como invisiveis ou excluídos das estatísticas - população em situação de rua, adolescentes em conflito com a lei, indigenas, quilombolas, idosos, pessoas com deficiência (BRASIL, 2004, p. 16).

Em contrapartida, todos os gestores alegam que são necessárias políticas sociais para quilombolas, mesmo considerando que o CRAS
Quilombola seria um mecanismo de exclusão, e não de inclusão. A gestora de Teófilo Otoni alega que as políticas específicas são importantes "justamente para poder garantir os direitos, né. Para poder chegar até a população quilombola. As Políticas [...] precisam ter algo mais forte, mas que garanta mais o direito para eles" (Gestora de Teófilo Otoni, informação verbal). ${ }^{13}$ Em Pescador, a participante da gestão pondera: "vejo esse povo ainda sem alcançar seu direito, pelo menos aqui, eu estou falando da realidade de Pescador" (Gestora de Pescador, informação verbal). ${ }^{14}$

No municipio de Ataléia, a gestora destaca: "Eu acredito que seja válido, mas se for do jeito que eu estava te explicando, se for para comunidade num todo, não de forma individual. Aí acredito que o trabalho possa ser feito e deve ser feito com o intuito de valorizar a própria comunidade" (Gestora de Ataléia, informação verbal). ${ }^{15}$

O reconhecimento da importância das políticas setoriais especificas para as comunidades quilombolas é perceptivel, mostrando a consciência dos entrevistados sobre a necessidade de tais ações. As inconsistências entre ter CRAS Quilombola (como parte da política de assistência social) e ter políticas de ações afirmativas também são diversas.

As anotações do diário de campo e as observações sistemáticas dos espaços que visitamos para a realização das entrevistas nos permitem considerar que o desenvolvimento das medidas socioeducativas, principalmente as desenvolvidas pelo CRAS, não consideram a opinião dos usuários para criação e execução das oficinas. Essas são voltadas, na maioria das vezes, para o artesanato e a escolha das oficinas parte de cima para baixo, sem contar com a participação dos interessados. Esse fator conduz ao esvaziamento das atividades, principalmente quando o público-alvo são os adultos.

\footnotetext{
12 Depoimento do(a) implementador(a) da política de assistência social do municipio de Ouro Verde de Minas à pesquisadora Sidimara Cristina de Souza, em entrevista realizada em 2020

13 Depoimento da gestora da Política de Assistência Social do município de Teófilo Otoni-MG à pesquisadora Sidimara Cristina de Souza, em entrevista realizada em 2020.

14 Depoimento da gestora da Política de Assistência Social do municipio de Pescador-MG à pesquisadora Sidimara Cristina de Souza em entrevista realizada em 2020

15 Depoimento da gestora da Política de Assistência Social do municipio de Ataléia-MG à pesquisadora Sidimara Cristina de Souza, em entrevista realizada em 2020
} 
Em Pescador, é desenvolvida a oficina de capoeira, tanto na cidade como na comunidade quilombola. Porém, não houve discussão para implantar essa modalidade cultural/esportiva. Os gestores apenas tomaram a decisão ao determinar que teriam como público-alvo crianças e adolescentes de uma comunidade quilombola. Por esse motivo, seria supostamente necessário resgatar a capoeira como símbolo cultural daquele grupo.

Sabemos que as medidas socioeducativas fazem parte das atividades propostas dentro do desenho política da assistência social, porém é necessário que essas ações sejam materializadas de forma mais participativa e propositiva. Elas também devem ser adaptadas de acordo com as fases da vida em que encontram os usuários (infância, juventude, velhice, adulta), suas demandas e expectativas.

No município de Teófilo, o entrevistado do CREAS alega que atendeu três familias quilombolas, mas que só foi saber que eram oriundas de uma comunidade quilombola depois, porque o atendimento foi feito sem adentrar na questão identitária. Isso ocorreu, porque: "I...] no CREAS a gente atende geral, igual como a gente atendeu este caso, mas sem que a gente tenha uma percepção prioritária, porque prioritário são todos os casos aqui no CREAS. Então, a gente atendeu como prioridade geral, não especifico". (Representante do CREAS de Teófilo Otoni, informação verbal). ${ }^{16}$

Justamente porque todos os casos são prioridade é que a política deveria se voltar para cada um de forma singular sem desconsiderar a totalidade, diagnosticando as caracteristicas particulares de cada grupo que demanda pelos serviços da assistência social. A carência de informação, o desconhecimento e a falta de cuidado com o outro na hora do atendimento podem conduzir a um atendimento falho e sem garantias de direitos. Isso leva, consequentemente, à inoperância da ação. Por isso, precisamos prezar pelo acesso de qualidade, que de fato proporcione equidade e bem-estar social. Isso só é possivel quando a política é operada de modo que respeite as diferenças do outro.

De acordo com os entrevistados de Carlos Chagas, a política de assistência social chega até as comunidades quilombolas, mas não da mesma forma que é implementada na zona urbana. Isso acontece por causa da distância entre os implementadores da politica e os usuários. Essa situação, de acordo com a gestora de Pescador, não acontece no território dela.

Para a entrevistada da gestão da Secretaria de Assistência Social de Teófilo Otoni, as políticas de assistência social chegam de forma limitada. "Na verdade, por causa das dificuldades que tem para chegar né, acesso que eu te falei, sem internet, sem condição. Então eu acho que vai mais a questão estrutural, não tem uma estrutura para poder fazer esse atendimento" (Gestora de Teófilo Otoni, informação verbal). ${ }^{17}$

Em Ouro Verde, porém, a gestora e um entrevistado do CRAS destacam que as ações de assistência social não chegam aos quilombolas. De acordo com o representante da gestão do municipio, nenhum serviço ou programa de assistência social chega até à zona rural, porque a secretaria não tem condições de atender esse público, ".... por falta de recurso, e não tem estrutura para poder levar, ofertar só para as comunidades quilombolas ou para outra comunidade [...]". Contudo, a entrevistada pontua: "só que a gente deixa bem claro que a porta está aberta para todas as comunidades" (Representante da Gestão de Ouro Verde de Minas, informação verbal). ${ }^{18}$

Segundo as entrevistadas do CRAS de Ouro Verde de Minas e de Teófilo Otoni, o não atendimento das comunidades quilombolas se justifica por uma questão de recursos. Contudo, também

\footnotetext{
16 Depoimento do implementador da Política de Assistência Social do município de Teófilo Otoni-MG à pesquisadora Sidimara Cristina de Souza, em entrevista realizada em 2020.

17 Depoimento da gestora da Política de Assistência Social do municipio de Teófilo Otoni-MG à pesquisadora Sidimara Cristina de Souza, em entrevista realizada em 2020.

18 Depoimento da representante da gestão de Política de Assistência Social do municipio de Ouro Verde de Minas-MG à pesquisadora Sidimara Cristina de Souza, em entrevista realizada em 2020.
} 
é explicado pelos seguintes motivos:

É, quadro de profissional pequeno. Os profissionais, são poucos profissionais para muito trabalho. E a questão da locomoção também, que no momento o carro que é da Assistência não está exclusivo para Assistência. Não está atendendo a Assistência, está atendendo a saúde também, né, outra Secretaria, e acaba dificultando um pouco, o trabalho da gente (Representante do CRAS de Ouro Verde de Minas, informação verbal). ${ }^{19}$

Para a representante do CREAS de Teófilo Otoni, a política chega aos quilombolas da mesma forma que para os demais.

Porque a gente atende à demanda aqui, é via Judiciário, via Ministério Público ou conselho Tutelar. Então ela é ampla, de onde vir a gente vai atender. Então a gente, as vezes tem alguma demanda especifica que seja de demanda é, espontânea que chega aqui, a gente atende também, mas normalmente é encaminhado quando precisa (Representante do CREAS de Teófilo Otoni, informação verbal). ${ }^{20}$

Parte dos participantes da pesquisa relatam que a política de assistência social chega às comunidades quilombolas, seja via mutirão para cadastro/renovação no Cadúnico seja via CRAS. Esses programas e serviços que chegam têm efeito positivo na comunidade. Isso porque:

[...] porque geralmente eles, esse pessoal quilombola, não só quilombola, mas pessoal da área rural em geral, maioria né, eles são pessoas muito assim, de pouca informação. Então, quanto mais informação chega até ele, quanto mais trabalho a gente desenvolve com ele e solução de trabalho que a gente traz, quais são o direito que cada um tem, os direitos que eles podem adquirir, direitos que muitas vezes eles nem sabem que existem, e eles não sabem por falta de informação deles. Então, as vezes a gente vai, a gente percebe o que o uma pessoa por exemplo, uma situação que uma familia está passando por exemplo, e algo que seria um direito, um benefício, algum direito assim que ele tem desconhecimento, ele passa a conhecer, juntamente com o tra- balho que a gente desenvolve. Então como tem um pessoal de muita pouca informação, esse é trabalho é muito importante, bastante positivo, justamente por essa questão, por se estender, ser mais serviço, entender quais são os direitos deles. Muitas vezes eles não sabem qual que é o serviço que o CRAS, qual que é o serviço da Secretaria, então muitas vezes eles ficam. Até quando vem a palestras aqui no municipio eles ficam até sem saber onde é o Bolsa Família, onde é que faz acompanhamento de familia, então tudo isso é importante enquanto objetivo. Para que eles possam saber os diretos deles e possam buscar esse direito junto a Assistência Social (Representante do CRAS de Carlos Chagas, informação verbal). ${ }^{21}$

Na percepção dos pesquisados, a informação sobre os direitos e, consequentemente, o acesso a esses direitos são os principais efeitos da politica de assistência social nas comunidades. O entrevistado do CRAS de Pescador relata que teria um efeito mais significativo "se ficasse acompanhado mais de perto, a gente está ali continuadamente, acho que teria mais efeito, acho que falta isso. Falta isso, ter acompanhado mais de perto, para ter mais positividade" (Representante do CRAS de Pescador, informação verbal). ${ }^{22}$

De uma forma geral, podemos considerar que as políticas de assistência social chegam às comunidades quilombolas, porém, de uma forma muito limitada e precária. Mesmo com a ampliação de divulgação dos serviços e dos programas ofertados pela assistência social a partir dos anos 2000, a carência de comunicação entre implementadores, gestores e usuários é grande, principalmente se tratando de territórios rurais, situação que inviabiliza a chegada das ações da assistência social.

Dentro das áreas de atuação dos entrevistados, questionamos se havia algum foco específico para as comunidades quilombolas e, se não havia, pedimos para justificarem o porquê. A maioria dos

\footnotetext{
19 Depoimento da implementadora da Política de Assistência Social do município de Ouro Verde de Minas-MG à pesquisadora Sidimara Cristina de Souza, em entrevista realizada em 2020.

20 Depoimento da implementadora da Política de Assistência Social do município de Teófilo Otoni-MG à pesquisadora Sidimara Cristina de Souza, em entrevista realizada em 2020

${ }_{21}$ Depoimento da implementadora da Política de Assistência Social do municipio de Carlos Chagas-MG à pesquisadora Sidimara Cristina de Souza, na ocasião da entrevista realizada em 2020.

22 Depoimento da implementadora da Política de Assistência Social do municipio de Pescador-MG à pesquisadora Sidimara Cristina de Souza, em entrevista realizada em 2020.
} 
participantes sabia que, no formulário do CadÚnico, há uma categoria para definir se o usuário é quilombola, porém, em nenhum município, foi desenvolvida uma atividade que tenha foco exclusivo para esse grupo. A justificativa foi sempre amparada pelo discurso utópico da universalidade. da garantia de direitos iguais para todos. O que se torna uma falácia diante de um país tão desigual como o nosso.

O direcionamento do atendimento, do processo de implementação da política de assistência social para a amplitude do todo impossibilita o conhecimento das partes, o que é visivel quando questionamos o número de beneficiados pelo BPC e pelo Programa Bolsa Familia. Os entrevistados não sabem informar a quantidade de usuários quilombolas inseridos nos dois programas. Primeiro, porque não há preocupação em identificar quem é ou não quilombola, uma vez que buscam trabalhar com o olhar direcionado exclusivamente para "se se enquadram ou não no perfil", independentemente da autoatribuição identitária. Esquecem-se, dessa forma, que esse indicador é um elemento também considerado pela política de assistência social, principalmente a partir da PNAS.

O desconhecimento pode ser justificado pela carência de diagnósticos nos municípios, um instrumento que deixaria os implementadores e gestores mais informados sobre a população usuária da assistência social e do contexto local como um todo. Todavia, temos que considerar que, desde a promulgação da Constituição Federal de 1988 até a contemporaneidade, analisa-se a assistência social como um direito de todos, porém, sem considerar que a identidade negra no Brasil é um indicador de risco e de vulnerabilidade social, principalmente no que tange à questão racial. Questão essa que vem sendo historicamente minimizada pelo mito da democracia racial. Nesse sentido, os grupos que assumem a negritude estarão automaticamente inseridos em um espaço de vulnerabilidade.

Nesse contexto, é preciso criar espaços de diálogo, para além das conferências municipais, estaduais e federais, para debater sobre a assistência social como política de direito de todas(os). Isso significa considerar as especificidades, principalmente dos grupos com identidades estigmatizadas - como é o caso das comunidades quilombolas.

\section{Considerações finais: os gargalos da PNAS junto aos remanescentes de quilombos}

São vários os empecilhos que possibilitam a instabilidade e a incompletude das políticas sociais brasileiras, principalmente no que tange à política de assistência social e do seu processo de operacionalização em municipios de pequeno e médio porte. Nesses locais, o apadrinhamento, o favoritismo, o clientelismo e o jeitinho brasileiro são muito presentes. É por isso que consideramos os embates partidários um dos principais gargalos da política de assistência social. As incompletudes atreladas a uma briga de egos para não "favorecer o concorrente" conduzem à inoperância das politicas sociais. Desconsidera-se o interesse social em prol de objetivos partidários referentes à manutenção, chegada ou retomada do poder em âmbito local.

Outro gargalo significativo é a fantasia comunitária, pois ela leva a uma não política ou a políticas setoriais fracassadas, como podemos observar. Os entrevistados reconhecem que a politica de assistência social prevê algum tipo de atendimento prioritário aos quilombolas, contudo, não sabem quais, por não terem claro quais são os direitos dessa população. Principalmente, por trabalharem no viés da universalidade, partindo do pressuposto que todos são iguais, o critério de especificidade é tido como um processo discriminatório.

Essa consciência pode se tornar uma restrição de acesso, acarretando a inoperância das políticas sociais por meio de traços que reforçam o conservadorismo e invisibilizam as singularidades de grupos minoritários, como é o caso das comunidades quilombolas. A subalternidade é reafirmada no processo de coletividade, ao desconsiderar as particularidades de núcleos tomados como "diferentes". Isso impossibilita a equidade. Esses processos contribuem para a criação de "políticas casuísticas e fragmentadas, sem regras estáveis e operando em redes públicas obsoletas e deterio- 
radas" (YAZBEK, 2001, p. 37), que não possibilitam a garantia de direitos e, quando o fazem, é de forma precária, seletiva e focalista.

A carência dos espaços de constituição dos CRAS nos municipios de Ouro Verde de Minas, Carlos Chagas, Teófilo Otoni e Ataléia são representativas. A primeira fragilidade está na ausência de uma sede própria para efetivação dos serviços, fator que, muitas vezes, impossibilita a criação de vínculo entre o usuário e o espaço de atendimento. Uma segunda carência diz respeito à ausência de estrutura física adequada que resguarde o sigilo profissional e não exponha o usuário em atendimento. Há, ainda, ausência de profissionais para realizar o atendimento, sem contar a instabilidade dos funcionários, que, na sua maioria, são terceirizados e dispensados de acordo com os interesses politicos locais.

De 2016 até hoje, a política social brasileira vem sofrendo um grande desmonte. Esse processo teve início com a aprovação da Emenda à Constituição n 55, de 2016 (PEC 241/2016), também conhecida como PEC do Teto dos Gastos Públicos. A normativa estabelece o Novo Regime Fiscal na esfera dos Orçamentos Fiscal e da Seguridade Social da União. O teto vigorará por 20 exercícios financeiros, com limites para as despesas primárias de cada um dos três poderes, do Ministério Público da União e da Defensoria Pública da União. Essa medida faz com que os investimentos para financiamento das politicas sejam muito reduzidos.

No que diz respeito à política de assistência social, o corte de gastos é grande e se reflete na diminuição ou na extinção de programas e projetos sociais. De acordo com o Conselho Nacional de Assistência Social - CNAS (2019), a redução dos gastos com a assistência social em 2017 foi de $21,76 \%$. Esse desfalque chegou a 37,52\% em 2018 e, em 2019, a 29,16\%.

De acordo com o CNAS (2019), os cortes no orçamento representam menos atendimentos nos CRAS, atingindo cerca de 10 milhões de pessoas e de famílias por ano. São individuos que estão em situação de desemprego, fome, eminência de violência doméstica, entre outras refrações da questão social. Estima-se, também, redução de aproximadamente $50 \%$ dos atendimentos nos CREAS a pessoas e familias em situação de violência doméstica ou comunitária. Prevê-se ainda redução dos atendimentos às pessoas em situação de rua e risco de fechar casas de acolhimento e dos centros POP.

Outra consequência deve ser o corte das equipes que atuam em serviços de acolhimento institucional, como os abrigos, casas lar, casas de passagem e residências inclusivas. Esse fato pode representar a diminuição de 133 mil vagas de trabalho e reduzir 58 mil vagas para idosos e 27 mil para adultos desabrigados ou em situação de rua. Podemos ter ainda a diminuição das equipes de atendimento e de identificação das pessoas em situação de rua. Em resumo, como podemos observar, estamos caminhando para a inviabilização das ações da assistência social por falta de recursos financeiros, materiais e humanos.

A extinção do Ministério do Desenvolvimento Social, que foi acoplado ao Ministério da Cidadania, também representa um contexto de perdas significativas, uma vez que retira a autonomia da pasta e diminui o valor orçamentário disponivel para a efetivação da agenda política da assistência social. Tudo isso ocorre com o objetivo de "enxugar a máquina pública".

Desafios que tendem a se ampliar com o congelamento e a ampliação da burocratização (Decreto n 9.739 de 2019) dos concursos públicos e a inibição da participação popular e do controle social (Decreto 9. 759 de 2019, que diminui o número de conselhos participativos ${ }^{23}$ previstos pela Política Nacional de Participação Social - PNPS e pelo Sistema Nacional de Participação Social - SNPS). Enfim, vemos a precarização do sistema público brasileiro em nome de uma nova contrarreforma, que tende cada vez mais a responsabilizar os indivíduos pela garantia do seu bem-estar social. Em tempos de crise, é bom lembrar que a política

${ }_{23}$ Entre os conselhos, temos importantes representatividades das minorias: o Conselho Nacional dos Direitos da Pessoa com Deficiência (CONADE), o Conselho Nacional de Combate à Discriminação e Promoção dos Direitos de LGBT (CNCD/LGBT), o Conselho Nacional de Erradicação do Trabalho Infantil (CONAETI), o dos Direitos do Idoso (CNDI), a Comissão Nacional de Política Indigenista (CNPI), Coordenação Nacional de Articulação das Comunidades Negras Rurais Quilombolas (CONAQ), o Conselho Nacional dos Povos e Comunidades Tradicionais (CNPCT). 
de assistência social é sempre a primeira a sofrer cortes (SPOSATI, 2011).

Por fim, nos cabe afirmar que, no momento, só resta aos remanescentes de quilombos continuarem resistindo, pois, os tempos são de desmantelamento dos poucos direitos que ainda restam. Como garantir políticas de reconhecimento e redistribuição para grupos invisibilizados como sujeitos de direitos em tempos de legitimação ideológica do mito da democracia racial e, ao mesmo tempo, de implementação de uma agenda econômica ultraliberal? Precisamos, mais do que nunca, reafirmar a equação apresentada por Guimarães (2009, p. 238): "um Estado = várias heranças culturais = várias raças = várias etnias". Por isso, precisamos continuar resistindo e reconhecendo a importância das identidades grupais para a criação e efetivação de políticas sociais mais eficazes.

\section{Referências}

ALMEIDA, M. Familia Negra: 'filha de estranho' na sociedade brasileira. In: ENCONTRO NACIONAL DE PESQUISADORES EM SERVIÇO SOCIAL, 15., 2016, Ribeirão Preto. Anais [...]. Ribeirão Preto: ENPRESS, 2016.

BARROCO, M. L.; TERRA, S. H. Código de ética do/a assistente social comentado. São Paulo: Cortez, 2012.

BEHRING, E. R. Balanço Critico do SUAS e o Trabalho do/a Assistente Social. In: Conselho Federal de Serviço Social. Seminário Nacional O trabalho do/a Assistente Social no SUAS. Brasilia: CFESS, 2011. p. 84-95.

BRANDÃO, A. et al. Comunidades quilombolas no Brasil: características socioeconômicas, processos de etnogênese e políticas sociais. Rio de Janeiro: Eduff, 2010.

BRASIL. Ministério do Desenvolvimento Social e Combate à Fome; Secretaria Nacional de Assistência Social Politica Nacional da Assistência Social. Ministério do Desenvolvimento Social e Combate à Fome. Brasilia: Ministério do Desenvolvimento Social e Combate à Fome; Secretaria Nacional de Assistência Social, 2004. Disponivel em: http://www.sesc.com.br/mesabrasil/doc/Pol\%C3\%ADtica-Nacional.pdf. Acesso em: 6 jul. 2016.

BRASIL. SEPPIR. Programa Brasil Quilombola. Brasília: Secretaria Especial de Politicas de Promoção da Igualdade Racial -SEPPIR, 2013. Disponivel em: http://WWW. seppir.gov.br/portal-antigo/arquivos-pdf/quia-pbq. Acesso em: nov. 2017.

BRASIL. SEPPIR. Programa Brasil Quilombola. Secretaria Especial de Políticas de Promoção da Igualdade Racial-SEPPIR. Brasilia, DF: Secretaria de Políticas de Promoção da Igualdade Racial (SEPPIR), 2017. Disponivel em: http://monitoramento.seppir.gov.br/paineis/pbq/ index.vm?eixo=3. Acesso em: 12 nov. 2017.
BRASIL. Decreto $n^{\circ}$ 9.739, de 28 de março de 2019. Estabelece medidas de eficiência organizacional para o aprimoramento da administração pública federal direta, autárquica e fundacional, estabelece normas sobre concursos públicos e dispõe sobre o Sistema de Organização e Inovação Institucional do Governo Federal - SIORG. Planalto, Brasilia, DF, 2019. Disponivel em: http://www.planalto.gov.br/ccivil_03/_ato20192022/2019/decreto/D9739.htm. Acesso em: 17 de jun. 2019.

BRASIL. Decreto $n^{\circ}$ 9.759, de 11 de abril de 2019. Extingue e estabelece diretrizes, regras e limitações para colegiados da administração pública federal. Planalto, Brasília, DF, 2019. Disponivel em: http://www.in.gov.br/ materia/-/asset_publisher/KujrwoTZC2Mb/content/ id/71137350/do1e-2019-04-11-decreto-n-9-759-de-11de-abril-de-2019-71137335. Acesso em: 10 dez. 2019.

BRASIL. Proposta de Emenda à Constituição no 241-a, de 2016. Altera o Ato das Disposições Constitucionais Transitórias, para instituir o Novo Regime Fiscal, e dá outras providências. Câmara dos Deputados, Brasília, DF, 2016. Disponivel em: https://www.camara.leg.br/ proposicoesWeb/prop_mostrarintegra:jsessionid=707DBEA2C7955711FC6BA48AD7EA4E93.proposicoesWebExterno2?codteor $=1495741 \&$ filename $=$ Tramitacao-PEC+241/2016. Acesso em: 17 jul. 2018.

BRASIL. Lei no 13.429, de 31 de março de 2017. Altera dispositivos da Lei $n^{\circ} 6.019$, de 3 de janeiro de 1974 . que dispõe sobre o trabalho temporário nas empresas urbanas e dá outras providências; e dispõe sobre as relações de trabalho na empresa de prestação de serviços a terceiros. Brasilia, DF: Planalto, 2017. Disponivel em: http://www.planalto.gov.br/ccivil_03/_ato20152018/2017/lei/L13429.htm. Acesso em: 17 jun. 2019.

BRASIL. Portaria MDS no 442 de 26 de agosto de 2005 Regulamenta os Pisos da Proteção Social Básica estabelecidos pela Norma Operacional Básica - NOB/ SUAS, sua composição e as ações que financiam. Brasilia, DF: Câmara Legislativa, 2005. Disponivel em: https://Www. legisweb.com.br/legislacao/?id=192987. Acesso em: 17 jul. 2018.

BRASIL. Portaria MDS no 137 de 25 de abril de 2006. Estabelece normas de Cooperação técnica e financeira de Projetos para Estruturação da Rede de Proteção Social Básica do Sistema Único de Assistência Social em 2006. Brasilia, DF: Ministro de Estado do Desenvolvimento Social e Combate à Fome, 2006. Disponivel em: https://www.mds.gov.br/webarquivos/legislacao/assistencia_social/portarias/2006/Portaria\%20 MDS\%20no\%20137-\%20de\%2024\%20de\%20abril\%20 de\%202006.pdf. Acessado em: 14 jun. 2019.

BRASIL. Resolução no 109, de 11 de novembro de 2009 Tipificação Nacional dos Serviços Socioassistenciais. Brasilia, DF: Conselho Nacional de Assistência Social, 2009. Reimpressão 2014. Disponivel em: https://www. mds.gov.br/webarquivos/publicacao/assistencia_social/Normativas/tipificacao.pdf. Acesso em: 17 jun. 2018.

CONSELHO NACIONAL DE ASSISTÊNCIA SOCIAL CNAS. Nota Referente ao Déficit Orçamentário da Politica de Assistência Social. Brasilia, DF: Conselho Nacional De Assistência Social-CNAS, 11 abr. 2019. Disponivel em: file:///C:/Users/sidim/Downloads/nota-deficit-orçamentario-atualizada.pdf. Acesso em: 28 jun. 2019. 
COUTO, Berenice Rojas; YAZBEK, Maria Carmelita; RAICHELIS, Raquel. A Política de Assistência Social e o SUAS: apresentando e problematizando fundamentos e conceitos. In: COUTO, Berenice Rojas et AL. (org.). O Sistema Único de Assistência Social no Brasil: uma realidade em movimento. São Paulo: Cortez, 2010. p. 32-65.

DATAUFF. Avaliação da Situação de Segurança Alimentar e Nutricional em Comunidades Quilombolas Tituladas. Niterói, RJ: DATAUFF - Núcleo de Pesquisa da Universidade Federal Fluminense. Fundação Euclides da Cunha de Apoio Institucional à Universidade Federal Fluminense (FEC-UFF) Núcleo de Pesquisas Sociais Aplicadas, Informações e Políticas Públicas da Universidade Federal Fluminense (DATAUFF), 2012. Relatório de Pesquisa.

DAHL, Robert Alan. Poliarquia: Participação e Oposição. São Paulo: Editora Universidade de São Paulo, 1997.

FUNDAÇÃO CULTURAL PALMARES. Comunidades Remanescentes de Quilombo (CRQs)., Brasilia, DF: Fundação Cultural Palmares, 2019. Disponivel em: http:// www.palmares.gov.br/comunidades-remanescentes-de-quilombos-cras. Acesso em: 12 jan. 2020.

GUIMARÃES, Antonio Sérgio. GUIMARÃES, Antonio S. Classes, Raças e Democracia no Brasil. São Paulo: Ed.34, 2009.

GUERRA, Yolanda Aparecida Demétrio. No que se sustenta a falácia de que na prática a teoria é outra? Rio Grande do Norte: CRESS, 2004. Disponivel em: http://www.cressrn.org.br/files/arquivos/5psf5T38gobx1M5sq112.pdf. Acesso em: 15 dez. 2021.

MENDOSA, Douglas. Gênese da politica de assistência social no governo Lula. 2012. Tese (Doutorado em Sociologia) - Universidade de São Paulo, 2012.

SPOSATI, Aldaiza de Oliveira. A menina Loas: um processo de construção da assistência social. 6. ed. São Paulo: Cortez, 2011

YAZBEK, Maria Carmelita. Classes subalternas e assistência social. São Paulo: Cortez, 1993.

YAZBEK, Maria Carmelita. Pobreza e exclusão social: expressões da questão social. Vitória-Espirito Santo: Revista Temporalis, ano III, n. 3, p. 33-40, jan./jun. 2001.

\section{Sidimara Cristina Souza}

Doutora e mestre em Política Social pelo Programa de Estudos Pós-Graduados em Política Social da Universidade Federal Fluminense (UFF), em Niterói, RJ, Brasil. Graduada em Serviço Social pela Universidade Federal dos Vales do Jequitinhonha e Mucuri (UFVJM), em Diamantina, MG, Brasil.

\section{André Augusto Pereira Brandão}

Doutor em Ciências Sociais pela Universidade do Estado do Rio de Janeiro (UERJ), no Rio de Janeiro, RJ, Brasil. Mestre em Sociologia e Antropologia pela Universidade Federal do Rio de Janeiro (UFRJ), no Rio de Janeiro, RJ, Brasil. Professor titular da Universidade Federal Fluminense (UFF), em Niterói, RJ, Brasil.

\section{Endereço para correspondência}

André Augusto Pereira Brandão

Universidade Federal Fluminense

Rua Miguel de Frias, 9

24220-90

Icaraí, Niterói, RJ

Os textos deste artigo foram revisados pela Poá Comunicação e submetidos para validação do(s) autor(es) antes da publicação. 